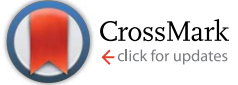

Cite this: RSC Adv., 2017, 7, 6931

\section{Infrared dichroism studies and anisotropic photoluminescence properties of poly(para- phenylene vinylene) functionalized reduced graphene oxide $\uparrow$}

\begin{abstract}
M. Baibarac, ${ }^{* a}$ M. Ilie, ${ }^{a b}$ I. Baltog, ${ }^{a}$ S. Lefrant ${ }^{c}$ and B. Humbert ${ }^{c}$
Two methods were used for the synthesis of composites based on reduced graphene oxide (RGO) and poly(para-phenylene vinylene) (PPV) in un-doped and doped state, respectively, i.e. the annealing conversion (AC) of the PPV precursor solution (PS) at $300{ }^{\circ} \mathrm{C}$ and the electropolymerization (E) of $\alpha, \alpha, \alpha^{\prime}, \alpha^{\prime}$-tetrabromo-p-xylene. In the case of the $\mathrm{E}$ method, a decrease in the distyrylbenzene (DSB) weight onto the RGO sheet surface in favor of PPV in doped state is demonstrated by the $s$ and $p$ polarized IR spectroscopy. The change of the orientation angle of the transition dipole moment vector for the IR bands at 835 and $964 \mathrm{~cm}^{-1}$, in the case of the AC of the PPV PS, is a result of the $\pi-\pi^{*}$ interactions between the phenyl groups of PPV and the RGO sheets. The photoluminescence (PL) bands at 2.42 and $2.26 \mathrm{eV}$ indicate the formation of PPV macromolecular chains (MCs) with lengths of 5 and 710 repeating units (RUs), respectively. The anisotropic PL studies performed on the composites RGO/PPV in un-doped and doped state, respectively, highlight an increase of the wrapping angle of RGO sheets with PPV MCs with lengths of 5 RUs, when graphene concentration increases.
\end{abstract}

Received 7th November 2016 Accepted 4th January 2017

DOI: $10.1039 / c 6 r a 26445 j$

www.rsc.org/advances
It is well known that the AC of the PPV PS results in a PPV in un-doped state. ${ }^{3}$ A partial and total conversion, respectively, of the PPV precursor solution occurs as the conversion temperature is increased from $100{ }^{\circ} \mathrm{C}$ to $300{ }^{\circ} \mathrm{C} .{ }^{3}$ Another method used to obtain PPV films in un-doped state was the electrochemical reduction of TBPX at potentials smaller than $-1.3 \mathrm{~V} \cdot{ }^{4,5}$ For the particular case of the composites based on PPV and singlewalled carbon nanotubes (SWCNTs), it was demonstrated that the chemical and E methods led to a non-covalent and a covalent functionalization, respectively, of SWCNTs with PPV in undoped state. ${ }^{5,6}$ To date, the transformation of the PPV films from un-doped state to a doped one was carried out either by chemical oxidation reactions in the presence of $\mathrm{FeCl}_{3}, \mathrm{I}_{2}$, or $\mathrm{H}_{2} \mathrm{SO}_{4}$ compounds $^{7}$ or by electro-oxidation of the un-doped PPV films. ${ }^{8}$ In the case of the electropolymerization of the monomers by cyclic voltammetry, depending on the potential at which cyclic voltammograms (CVs) were stopped, conjugated polymers (CPs) in un-doped or doped state ${ }^{9}$ were synthesized. In this work, we demonstrate that an alternative method to obtain the PPV films in doped state onto Au electrodes is cyclic voltammetry when the electrochemical polymerization reaction of TBPX in the potential range $(-2 ;+2) \mathrm{V}$ stopped the potential of $+2 \mathrm{~V}$ versus the $\mathrm{Ag} / \mathrm{AgCl}$ electrode. A goal of this work is to demonstrate that composites of the type RGO non-covalently functionalized with PPV in un-doped state and RGO covalently functionalized with PPV in doped state can be obtained by the AC of the PPV PS, having different RGO weight percentage
${ }^{a}$ National Institute of Materials Physics, Laboratory of Optical Processes in Nanostructured Materials, P.O. Box MG-7, RO-77125, Bucharest, Romania. E-mail: barac@infim.ro

${ }^{b}$ University of Bucharest, Faculty of Physics, P.O. Box MG-1, RO-77125, Bucharest, Romania

"Institut des Materiaux "Jean Rouxel”, 2 rue de la Houssiniere, B.P. 32229, F-44322, Nantes, France

$\dagger$ Electronic supplementary information (ESI) available. See DOI: 10.1039/c6ra26445j 
concentrations, and the electrochemical polymerization of TBPX in the presence of RGO, respectively, when the CVs were stopped at the potential of $+2 \mathrm{~V}$ versus the $\mathrm{Ag} / \mathrm{AgCl}$ electrode.

To establish the molecular structure of the composite materials synthesized by different methods, often the Raman scattering and Fourier transform infrared spectroscopy (FTIR) were used. Considering that the PPV/RGO composites were deposited as films onto the rough Au supports, the vibrational characterization of these materials by surface enhanced Raman scattering (SERS) and IR spectroscopy in the grazing angle incident reflection geometry will be shown in this paper. In the context of the progress recorded in the field of the vibrational properties of PPV and its composites, we note that recently reported studies of IR spectroscopy in the grazing angle incident reflection geometry concerning the dependence on the angle of polarization of the PPV films deposited on Ag and Au supports have allowed a better assessment of the orientation angle of the transition dipole moment vector for the IR absorption bands of macromolecular compounds in the case of the PPV/SWCNT composites prepared by the AC method of the PPV PS, having SWCNT difference weight percentage concentrations. ${ }^{10}$ Considering that in the present manuscript, the two synthesis methods of the PPV/RGO composites involve the use of rough Au supports, additional information concerning the orientation angle of the transition dipole moment vector for the PPV IR absorption bands will be also reported.

Despite the sustained effort concerning PL properties of the composite materials of the CPs/RGO type when a CP PL quenching effect induced by RGO often was demonstrated, ${ }^{\mathbf{1 0}}$ at present a confirmation that such process also occurs in the case of PPV/RGO composites is not reported. It is well known that polarized PL studies allow assessment of environmental changes. In the particular case of PPV, to date, special attention was given to the dependence of the PL spectra measured in polarized light with the conversion temperature of PPV PS ${ }^{11}$ and the assessment of the counter ions effect on energy transfer processes in PPV macromolecular chains (MCs). ${ }^{12}$ To our best knowledge, no further paper has been published concerning polarized-emission measurements to assess the influence of the carbon nanoparticles on the charge/energy transfer processes that occurs between the two constituents of the PPV/RGO composite. Using the mathematical algorithm previously shown ${ }^{\mathbf{1 3}}$ in this paper, special attention will be given to the calculation of anisotropy and the wrapping angle of RGO sheets with PPV MCs when the PPV/ RGO composites were prepared both by AC of the PPV PSs containing different RGO weight percentage concentrations and the electropolymerization of TBPX in the presence of RGO.

\section{Experimental}

\subsection{Materials}

Chemical compounds used in this work, i.e., $\alpha, \alpha^{\prime}$-dichloro- $p$ xylene, tetrahydrothiophene, $\mathrm{HCl}, \mathrm{NaOH}, \mathrm{NaCl}, \mathrm{CH}_{3} \mathrm{OH}$, tetrabutyl ammonium bromide (TBAB), dimethylformamide (DMF), graphite powder, $\mathrm{KMnO}_{4}, \mathrm{NaNO}_{3}, \mathrm{H}_{2} \mathrm{SO}_{4}, \mathrm{H}_{2} \mathrm{O}_{2}, \mathrm{C}_{2} \mathrm{H}_{5} \mathrm{OH}$, and hydrazine, were purchased from Aldrich-Sigma. Compound TBPX was purchased from Tokyo Chemical Industry Co., Ltd.

\subsection{Synthesis of reduced graphene oxide, poly(para- phenylenevinylene) and their composites}

Graphene oxide was prepared according to the protocol published by D. C. Marcano et al. and then reduced in the presence of hydrazine to obtain RGO. ${ }^{14,15}$

The PPV PS was synthesized using the method published by J. D. Stenger-Smith. ${ }^{16}$ Briefly, a solution of $0.75 \mathrm{M} \alpha, \alpha^{\prime}$-dichloro$p$-xylene $(6.5675 \mathrm{~g})$ in $\mathrm{CH}_{3} \mathrm{OH}(50 \mathrm{ml})$ was mixed with $3.75 \mathrm{M}$ tetrahydro-thiophene $(16.5 \mathrm{ml})$. The mixture was refluxed under magnetic stirring at the temperature of $50{ }^{\circ} \mathrm{C}$ for 12 hours. As increasing of the monomer concentration, the solution tends to yellow. A fraction of methanol $(35 \mathrm{ml})$ is extracted from above solution by distillation. The crystallization of the monomer is obtained by precipitation at $0{ }^{\circ} \mathrm{C}$ in distilled acetone $(500 \mathrm{ml})$, when a white precipitate results which is further dried. In order to improve the purity of monomer, the repeated dissolutions and re-crystallizations were carried out in order to eliminate non-dissolved monomer crystals and eventual impurities. The white crystals was dissolved in a polar solvents mixture (e.g. $\mathrm{CH}_{3} \mathrm{OH}: \mathrm{H}_{2} \mathrm{O}=17: 36$, volumetric ratio) at which was added a $\mathrm{NaOH}$ solution $(21.4 \mathrm{ml}, 1 \mathrm{M})$ by dropping under the purge with nitrogen gas. The excess of $\mathrm{NaOH}$ was neutralized with a $\mathrm{HCl}$ solution $(10 \mathrm{ml}, 1 \mathrm{M})$, until the $\mathrm{pH}$ becoming equal with 7 . Further, the solution is dialyzed in distillated water for ten days using a Spectra-Por Dialysis membrane in order to remove the un-reacted monomers and $\mathrm{NaCl}$. After this purification stage, the solution of poly( $p$-xylene tetra-hidrophenium chloride) is deposited as film onto rough Au support by the solvent evaporation under nitrogen atmosphere at $25{ }^{\circ} \mathrm{C}$. PPV PS films were annealed at $300{ }^{\circ} \mathrm{C}$ under vacuum at a pressure of $10^{-6}$ Torr for 10 hours. This AC process allows the remove of sulfonium groups leading to the appearance of the vinylene groups. In the case of PPV/RGO composites obtained by AC method, the PPV precursor/RGO blends with different weight percentages concentrations of RGO, equal to $0 \mathrm{wt} \%, 0.01 \mathrm{wt} \%, 0.05 \mathrm{wt} \%, 0.1$ $\mathrm{wt} \%$, and $0.5 \mathrm{wt} \%$, were prepared and ultrasonically homogenized for $10 \mathrm{~min}$, the AC taking place in the same conditions with those of PPV. Scheme $1 \mathrm{~S} \dagger$ shows the AC reaction of the PPV PS in the presence of RGO.

For electrochemical synthesis of the composites based on RGO and PPV in doped state, six solutions of $0.02 \mathrm{M}$ TBPX and $0.1 \mathrm{M}$ TBAB with different weight percentage concentrations of RGO, i.e., $0 \mathrm{wt} \%, 0.01 \mathrm{wt} \%, 0.025 \mathrm{wt} \%, 0.05 \mathrm{wt} \%, 0.1 \mathrm{wt} \%$, and $0.5 \mathrm{wt} \%$, in a solvent mixture of DMF and $\mathrm{H}_{2} \mathrm{O}$, having the volumetric ratio of $98: 2$, were prepared. The working electrode was a blank Au support with an area of $1 \mathrm{~cm}^{2}$, while the counter electrode was a spiral Pt wire; the reference electrode was a commercial $\mathrm{Ag} / \mathrm{AgCl}$ electrode $(3 \mathrm{M} \mathrm{KCl})$. Both PPV and the PPV/RGO composites were synthesized by cyclic voltammetry in the potential range of $(-2 ;+2) \mathrm{V}$ versus the $\mathrm{Ag} / \mathrm{AgCl}$ electrode at a sweep rate of $100 \mathrm{mV} \mathrm{s}^{-1}$. All CVs were stopped at the potential of $+2 \mathrm{~V}$ versus $\mathrm{Ag} / \mathrm{AgCl}, \mathrm{PPV}$ being in doped state. Scheme $2 \mathrm{~S} \dagger$ shows electrochemical mechanism of the covalent functionalization of the RGO sheets with PPV MCs.

A chemical treatment with a $1 \mathrm{M} \mathrm{NH}_{4} \mathrm{OH}$ solution of the composites based on RGO and PPV in doped state was 
performed to achieve a de-doping of the MCs when composites of the RGO/PPV type in un-doped state were expected to result.

\subsection{Characterization}

The CVs were recorded using a potentiostat/galvanostat from Radiometer Analytical, Voltalab 80 model.

Raman spectra were recorded in a backscattering geometry under an excitation wavelength of $676.4 \mathrm{~nm}$, using a T64000 Raman spectrophotometer from Horiba Jobin Yvon.

IR spectra were recorded using a Vertex 70 IR spectrometer from Bruker, endowed with a Hyperion 2000 FTIR microscope with a grazing angle objective.

PL spectra were recorded in a right-angle geometry, at room temperature (RT), using a Horiba Jobin Yvon Fluorolog-3 spectrophotometer, model FL3-22.

\section{Results and discussions}

\subsection{Electrochemical polymerization of TBPX in the presence of RGO}

The black curve in Fig. 1 corresponds to the 30th CV of the PPV film, electrochemical synthesized onto Au electrode, when four cathodic peaks at $-0.16 \mathrm{~V},-0.5 \mathrm{~V},-1.05 \mathrm{~V}$, and $-1.78 \mathrm{~V}$ versus $\mathrm{Ag} / \mathrm{AgCl}$ were observed. As shown in previously paper, ${ }^{5}$ during the cathodic scanning of the potential from +2 to $-2 \mathrm{~V}$ versus $\mathrm{Ag} / \mathrm{AgCl}$, the four cathodic peaks are also observed in the first 5 CVs, when the formation of a TBPX diradical was induced.

A consequence of the high chemical reactivity of TBPX diradicals toward themselves is the spontaneous dimerization reaction that leads to the formation of a dimer with the chemical formula of $\mathrm{Br}_{2} \mathrm{HC}-\mathrm{C}_{6} \mathrm{H}_{4}-\mathrm{CH}=\mathrm{CH}-\mathrm{C}_{6} \mathrm{H}_{4}-\mathrm{CHBr}_{2} \cdot{ }^{5}$ As numbers of

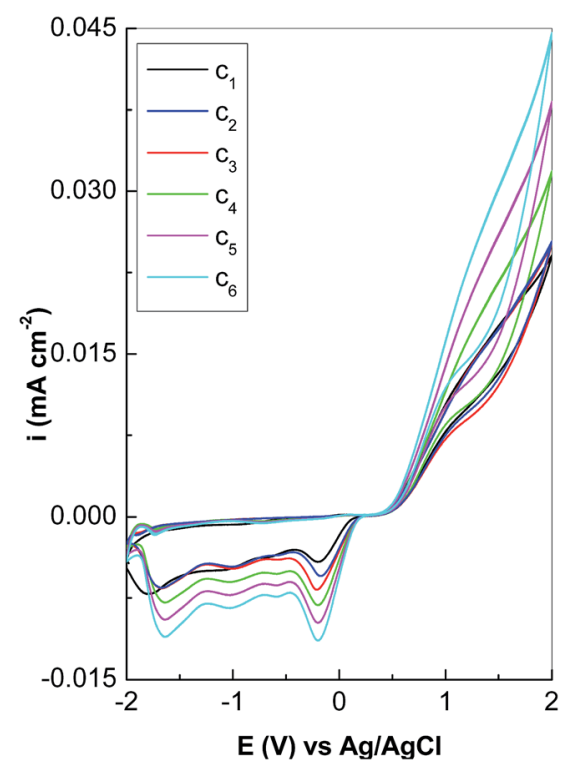

Fig. 1 The 30th CV recorded on the blank Au electrode immersed in the solutions of $0.02 \mathrm{M} \mathrm{TBPX}$ and $0.1 \mathrm{M} \mathrm{TBAB}$ in DMF : $\mathrm{H}_{2} \mathrm{O}$ containing different weight concentrations of RGO: 0 wt\% (black curve, $\mathrm{C}_{1}$ ), $0.01 \mathrm{wt} \%$ (dark blue curve, $c_{2}$ ), 0.025 wt\% (red curve, $c_{3}$ ), 0.05 wt\% (green curve, $\mathrm{c}_{4}$ ), $0.1 \mathrm{wt} \%$ (magenta curve, $\mathrm{c}_{5}$ ), and $0.5 \mathrm{wt} \%$ (open blue curve, $\mathrm{c}_{6}$ ).

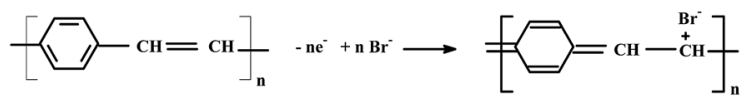

b

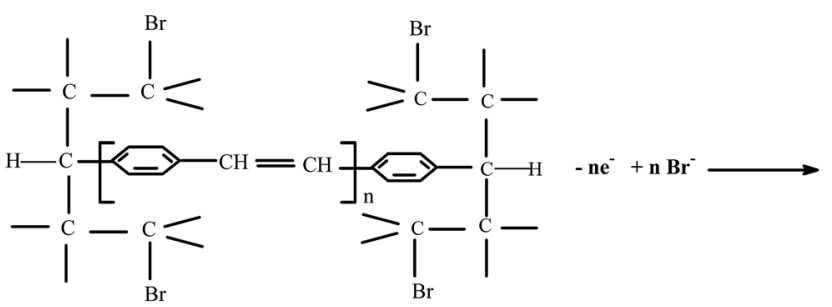

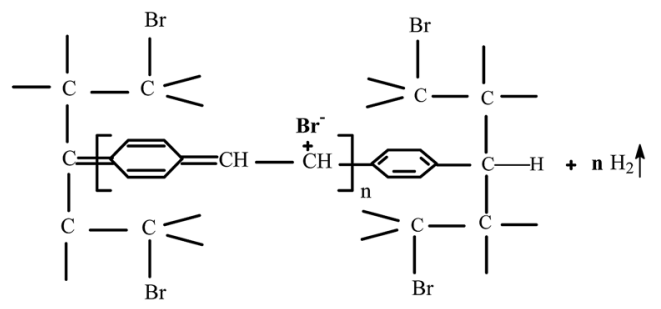

Scheme 1 The oxidation reaction of the film of PPV in un-doped state deposited onto the blank Au electrode in the absence of RGO (a) and in the presence of RGO (b).

CVs increase, successive reduction reactions of the dimer enable the growth of PPV MCs. ${ }^{5}$ Fig. 1 highlights an up-shift of the last cathodic peak from $-1.78 \mathrm{~V}$ to $-1.7 \mathrm{~V},-1.67 \mathrm{~V},-1.66 \mathrm{~V},-1.65 \mathrm{~V}$, and $-1.64 \mathrm{~V}$, as gradually increasing of the RGO weight percentage concentration from $0 \mathrm{wt} \%$ to $0.01 \mathrm{wt} \%, 0.025 \mathrm{wt} \%$, $0.05 \mathrm{wt} \%, 0.1 \mathrm{wt} \%$, and $0.5 \mathrm{wt} \%$, respectively. This change is accompanied by an increase in the current densities of the cathodic peaks at $-0.16 \mathrm{~V},-0.5 \mathrm{~V}$ and $-1.05 \mathrm{~V}$ versus $\mathrm{Ag} / \mathrm{AgCl}$. The preceding variations indicate that the reaction mechanism of the electrochemical synthesized PPV is changed in the presence of RGO when the formation of the RGO sheets covalently functionalized with the PPV oligomers in un-doped state is induced and occurs similar to how the composites based on PPV in un-doped state and SWCNTs highly separated in metallic and semiconducting tubes. ${ }^{5}$ During the anodic scanning of the potential from -2 to $+2 \mathrm{~V}$ versus $\mathrm{Ag} / \mathrm{AgCl}$, when the working electrode was immersed in the solution of $0.02 \mathrm{M}$ TBPX and $0.1 \mathrm{M}$ TBAB in DMF: $\mathrm{H}_{2} \mathrm{O}$, the development of a broad oxidation maximum $\sim+1.32 \mathrm{~V}$ versus $\mathrm{Ag} / \mathrm{AgCl}$ is observed in the case of the 30th CV of PPV. The presence of RGO in the synthesis solution induces, during the anodic scanning, only an increase of the current densities in the potential range $(+0.5 ;+2) \mathrm{V}$ versus $\mathrm{Ag} /$ $\mathrm{AgCl}$. The oxidation maximum at $\sim+1.32 \mathrm{~V}$ versus $\mathrm{Ag} / \mathrm{AgCl}$ is assigned to the insertion of the $\mathrm{Br}^{-}$ions into the PPV oligomer MCs according to reactions shown in Scheme 1.

\subsection{Vibrational and photoluminescence properties of the RGO/PPV composites}

Experimental arguments for the formation of the PPV oligomers in doped state onto the RGO sheets surface, as well as on the blank $\mathrm{Au}$ electrode, in the following are shown by surface enhanced Raman scattering (SERS) and IR spectroscopy in the grazing angle incident reflection geometry. 
Fig. 2 and 3 show Raman spectra of the PPV and RGO films deposited onto Au rough supports as well as of the PPV/RGO composites obtained by the electrochemical polymerization of TBPX and the AC of PPV PSs, respectively. We remind readers that the Raman spectrum of RGO (Fig. 2a) is characterized by the two bands situated at 1322 and $1596 \mathrm{~cm}^{-1}$, often labeled as the $\mathrm{D}$ and $\mathrm{G}$ bands of graphite materials, which are assigned to the breathing mode of the carbon hexagonal rings and the $\mathrm{E}_{2 \mathrm{~g}}$ phonon mode at the center of the Brillouin zone, respectively. ${ }^{15}$ Fig. 2f and $3 \mathrm{f}$ show the Raman spectra of the PPV films, synthesized by the electrochemical polymerization of TBPX and the method of AC of PPV PSs, respectively. Two Raman lines of high intensity are highlighted in the PPV Raman spectra, regardless of the synthesis method used. The former is located at $1174 \mathrm{~cm}^{-1}$, this being assigned to the $\mathrm{C}-\mathrm{C}$ stretching $+\mathrm{C}-\mathrm{H}$ bending of the phenyl ring vibrational mode $;^{17}$ the second one is peaked at $1591 \mathrm{~cm}^{-1}$, having two shoulders at $1550 \mathrm{~cm}^{-1}$ and $1629 \mathrm{~cm}^{-1}$. The three Raman lines at 1550,1591, and $1629 \mathrm{~cm}^{-1}$ are assigned to the vibrational modes of the $\mathrm{C}=\mathrm{C}$ stretching of the phenyl ring, $\mathrm{C}-\mathrm{C}$ stretching of the phenyl ring, and $\mathrm{C}=\mathrm{C}$ stretching of the vinyl group, respectively. ${ }^{17}$ In addition, the Raman spectra of the PPV, synthesized by the two methods, show a Raman line of lower intensity peaked at $1326 \mathrm{~cm}^{-1}$; that is attributed to the vibrational mode of $\mathrm{C}=\mathrm{C}$ stretching $+\mathrm{C}-\mathrm{H}$ bending of the vinyl group, ${ }^{17}$ and a Raman $\mathrm{G}$ band peaked at $\sim 1585-1588 \mathrm{~cm}^{-1}$ assigned to the $\mathrm{E}_{2 \mathrm{~g}}$ phonon mode at the center of the Brillouin zone. ${ }^{15}$

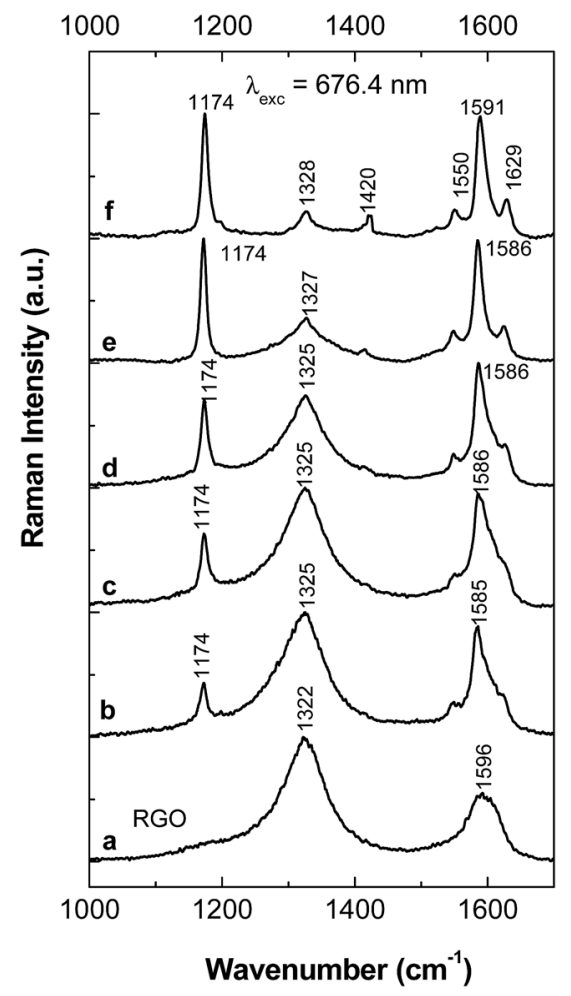

Fig. 2 The Raman spectra ( $\lambda_{\text {exc }}=676.4 \mathrm{~nm}$ ) of the films of RGO (a), PPV (f), and its composites electrochemical synthetized when the Au electrode was immersed in the solutions consisting of $0.02 \mathrm{M} \mathrm{TBPX}$, $0.1 \mathrm{M} \mathrm{TBAB}$, and different weight concentrations of RGO, i.e., $0.01 \mathrm{wt} \%$ (e), $0.05 w t \%$ (d), $0.1 w t \%$ (c), and $0.5 w t \%$ (b) in the DMF : $\mathrm{H}_{2} \mathrm{O}$.

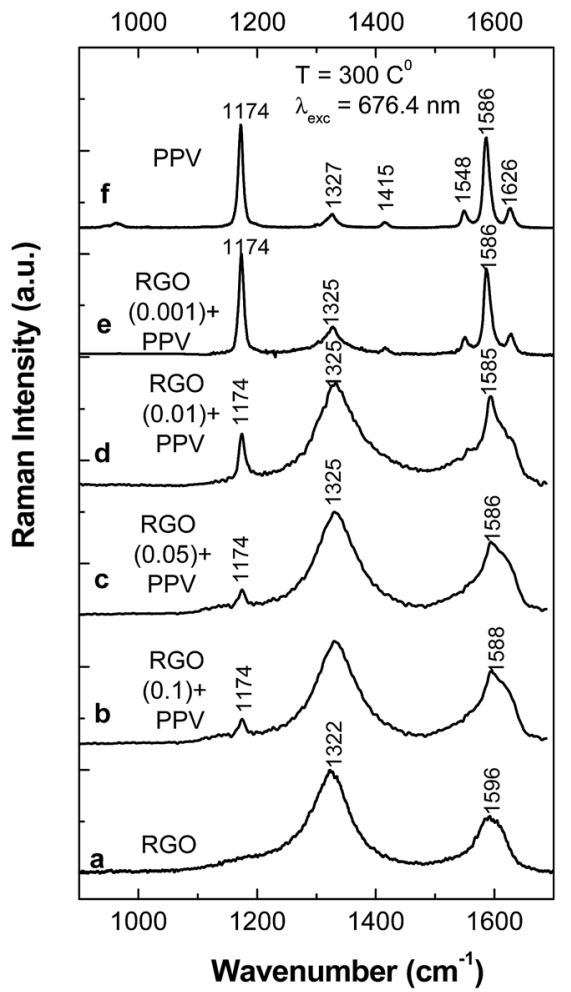

Fig. 3 The Raman spectra $\left(\lambda_{\text {exc }}=676.4 \mathrm{~nm}\right.$ ) of the films of RGO (a), PPV (f), and its composites synthesized by the AC of the PPV PSs with RGO weight percentages equal to $0.001 \mathrm{wt} \%$ (e), $0.01 \mathrm{wt} \%$ (d), 0.05 $w t \%$ (c), and $0.1 \mathrm{wt} \%$ (b).

Regardless of the synthesis method of the PPV/RGO composites, a gradual decrease in the relative intensity of the Raman line peaked at $1174 \mathrm{~cm}^{-1}$, accompanied by an increase in the relative intensity of the Raman band situated in the spectral range of $1200-1400 \mathrm{~cm}^{-1}$ (Fig. 2 and 3), is observed as the RGO weight percentage concentration in the composite mass increases. The only difference observed between the Raman spectra of the PPV films, synthesized by electrochemical and chemical method, i.e., when the polymer is in doped and un-doped state, respectively, is the position of the Raman line assigned to the symmetrical phenyl ring bending vibrational mode, ${ }^{17}$ which is changed from $1420 \mathrm{~cm}^{-1}$ (Fig. 2f) to $1415 \mathrm{~cm}^{-1}$ (Fig. 3f). Considering all these variations, in this stage of our studies, it is difficult to conclude that the two synthesis methods result in the formation of composites of the type RGO/ PPV in doped state and RGO/PPV in un-doped state. To overcome this inconvenience, Fig. 4 and 5 show the p and s polarized IR spectra of PPV and its composites synthesized by the two methods. In the case of the samples obtained by the AC of the PPV PS, at the temperature of $300{ }^{\circ} \mathrm{C}$, i.e., when the polymer oligomers are in un-doped state, the IR absorption bands at $\sim 837,963,1423$, and $1517 \mathrm{~cm}^{-1}$ (Fig. 4), assigned to the vibrational modes of phenyl ring $\mathrm{C}-\mathrm{H}$ out-of-plane bending, trans-vinylene $\mathrm{C}-\mathrm{H}$ out-of-plane bending, phenyl ring $\mathrm{C}=\mathrm{C}$ inplane bending and phenyl ring $\mathrm{C}-\mathrm{C}$ in-ring stretching, respectively, ${ }^{\mathbf{1 8 , 1 9}}$ show a dependence both with $\mathrm{s}$ and $\mathrm{p}$ polarization (as reported in ref. 18-20) and the RGO weight percentage concentration. 


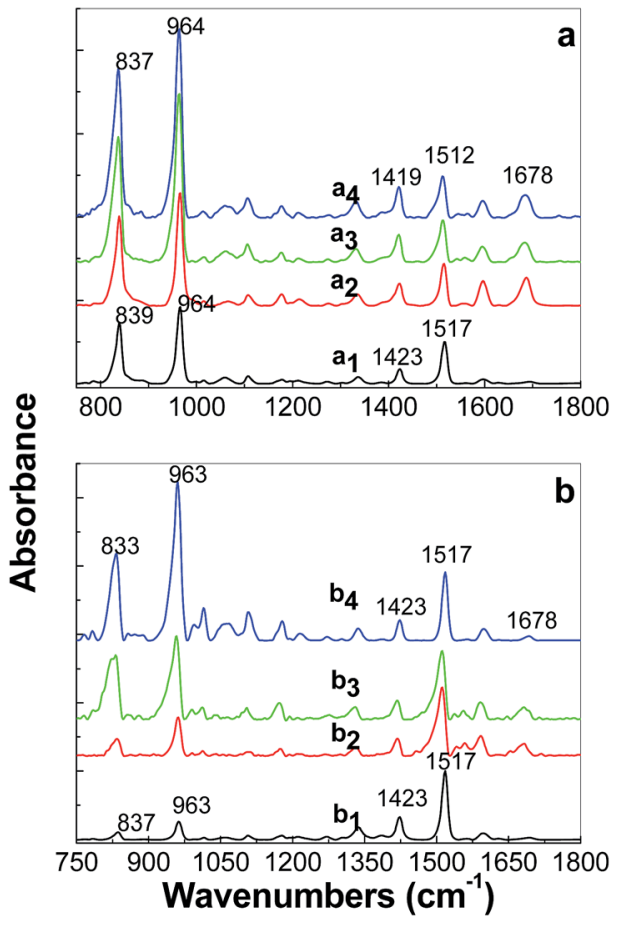

Fig. 4 The IR spectra of the PPV film deposited on an Au support, recorded in $\mathrm{p}(\mathrm{a})$ and s polarization (b), prepared by the AC of the PPV PS in the absence $\left(a_{1}\right.$ and $\left.b_{1}\right)$ and in the presence of the difference weight percentage concentrations of RGO equal with $0.01 \mathrm{wt} \%\left(\mathrm{a}_{2}\right.$ and $\left.b_{2}\right), 0.05 w t \%\left(a_{3}\right.$ and $\left.b_{3}\right)$, and $0.1 w t \%\left(a_{4}\right.$ and $\left.b_{4}\right)$.

A significant increase in the absorbance of the IR bands peaked at $\sim 837$ and $963-964 \mathrm{~cm}^{-1}$, as increase of the RGO weight percentage concentration in the PPV/RGO composite mass is observed in Fig. 4. These variations were reported to be characteristic for carbon nanoparticles-based materials such as SWCNTs non-covalently functionalized with PPV in un-doped state. $^{18-20}$

Table 1 shows the variation of the orientation angle of the transition dipole moment vector $\left(\theta_{\mathrm{IR}}\right)$ for the four IR absorption bands at $\sim 837,963,1423$, and $1517 \mathrm{~cm}^{-1}$ when the films of PPV with difference weight percentage concentration of RGO deposited onto Au supports were obtained by the AC of the PPV precursor/RGO blends at the conversion temperature of $300{ }^{\circ} \mathrm{C}$. A smaller variation of the orientation angle of the transition dipole moment vector is observed only in the case of the IR band peaked at $1516 \mathrm{~cm}^{-1}$. By analogy with the case of the PPV/SWCNT composites, obtained by the AC of the PPV PSs with different weight percentages concentrations of SWCNTs, at the conversion temperature of $300{ }^{\circ} \mathrm{C}$, the variation of the IR band peaking at $1517 \mathrm{~cm}^{-1}$, only by $4^{\circ}$, indicates an adsorption of the PPV noncovalently functionalized RGO composite onto the Au support through the $\mathrm{C}-\mathrm{C}$ stretching vibrational mode of the phenyl ring. ${ }^{20}$ In our opinion, the variations of $28^{\circ}$ and $41^{\circ}$ in the IR bands peaked at $\sim 833-837$ and $963-964 \mathrm{~cm}^{-1}$, as increasing the RGO weight percentage concentration in the PPV/RGO composite mass indicates significant perturbations induced by vibrational modes of phenyl ring $\mathrm{C}-\mathrm{H}$ out-of-plane bending and trans-
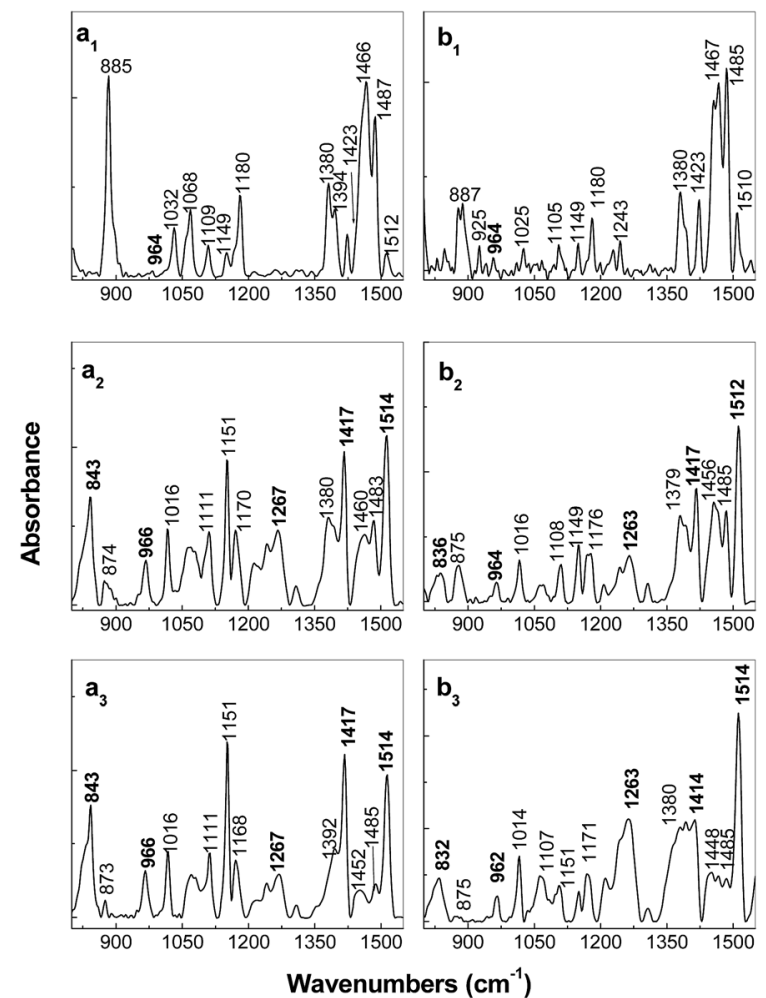

Fig. 5 The IR spectra of the PPV film deposited onto an Au support, recorded in $p(a)$ and $s$ polarization (b), prepared by the electropolymerization of TBPX in the absence $\left(a_{1}\right.$ and $\left.b_{1}\right)$ and in the presence of the difference weight percentage concentrations of RGO equal with $0.01 \mathrm{wt} \%\left(\mathrm{a}_{2}\right.$ and $\left.\mathrm{b}_{2}\right)$, and $0.1 \mathrm{wt} \%\left(\mathrm{a}_{3}\right.$ and $\left.\mathrm{b}_{3}\right)$.

vinylene $\mathrm{C}-\mathrm{H}$ out-of-plane bending, respectively, as a consequence of the $\pi-\pi^{*}$ interactions established between the basal plane of RGO and phenyl rings of the PPV MCs.

In this stage of our study, it is worth mentioning that the variation of $28^{\circ}$ noted in Table 1 for the IR band peaked at $\sim 833-837 \mathrm{~cm}^{-1}$, assigned to the vibrational modes of phenyl ring $\mathrm{C}-\mathrm{H}$ out-of-plane bending ${ }^{\mathbf{1 8 , 1 9}}$ fits well with the PPV torsion angles distribution $\Phi_{1}$ and $\Phi_{2}$ calculated by R. I. Venkatanarayanan et $a .^{21}$ to be equal with $27 \pm 1^{\circ}$. Comparison with the

Table 1 The values of the orientation angle of the transition dipole moment vector $\left(\theta_{\mathrm{IR}}\right)^{a}$ for the main IR bands of the samples deposited on Au supports, prepared by the AC of the PPV PS with different RGO weight percentage concentrations

\begin{tabular}{lllll}
\hline $\begin{array}{l}\theta_{\text {IR }} \\
(\text { degree }) \\
\left(\mathrm{cm}^{-1}\right)\end{array}$ & $\begin{array}{l}\theta_{\mathrm{IR}} \text { (degree) } \\
\text { for PPV/ }\end{array}$ & $\begin{array}{l}\theta_{\mathrm{IR}} \text { (degree) } \\
\text { for PPV/ }\end{array}$ & $\begin{array}{l}\theta_{\text {IR }} \text { (degree) } \\
\text { for PPV/ } \\
0.01 \mathrm{wt} \% \mathrm{RGO}\end{array}$ & $\begin{array}{l}\text { (d) } \mathrm{wt} \% \mathrm{RGO} \\
0.5 \mathrm{wt} \% \mathrm{RGO}\end{array}$ \\
\hline 835 & 82 & 80 & 72 & 54 \\
964 & 72 & 75 & 72 & 36 \\
1421 & 58 & 58 & 68 & 70 \\
1516 & 55 & 56 & 58 & 59
\end{tabular}

${ }^{a}$ The $\theta_{\mathrm{IR}}$ value was calculated with the following equation: ${ }^{18,20} R=$ $A_{\mathrm{p}} / A_{\mathrm{s}}=\left(\sin ^{2} \theta_{\mathrm{IR}}+o\right) /\left(2 \cos ^{2} \theta_{\mathrm{IR}}+o\right)$ where $A_{\mathrm{p}}, A_{\mathrm{s}}, R$ and $o$ correspond to the absorbance measured in the $\mathrm{s}$ and $\mathrm{p}$ polarization, the dichroic ratio and the orientation parameter equal with 0.04 . 
samples prepared by the AC method of the PPV PS with different weight percentage concentrations of RGO, in the case of the samples of PPV and its composites containing RGO and PPV in doped state, prepared by electrochemical polymerization of TBPX, significant differences are evidenced in Fig. 5. Fig. 5a $\mathrm{a}_{1}$ and $b_{1}$ show $p$ and $s$ polarized IR spectra of the compound electrochemical synthetized in the absence of RGO. The assignment of the IR absorption bands peaked at 885, 10251032 , 1068, 1105-1109, 1149, 1180, 1380-1394, 1423, 14661485, and $1512 \mathrm{~cm}^{-1}$ is shown in Table 1S. $\dagger$ Here, it is worth mentioning that the above IR absorption bands were reported belonging to PPV in doped state. ${ }^{7,18,22}$ The very low absorbance of IR bands peaked at 964 and $1518 \mathrm{~cm}^{-1}$, assigned to the vibrational modes of $\mathrm{C}-\mathrm{H}$ out-of-plane bending of trans-vinylene group and phenylene ring $\mathrm{C}=\mathrm{C}$ stretching, ${ }^{18,19}$ respectively (Fig. $5 a_{1}$ and $b_{1}$ ), must be understood taking into account the molecular structure of PPV in doped state obtained according to Scheme 1a. A puzzling fact is that these vibrational modes of PPV in doped state are located at the same frequencies as those reported in the case of distyryl benzene (DSB), a compound that shows three benzene rings and two vinyl groups. ${ }^{19}$ This fact allows advancing the hypothesis that by the electrochemical polymerization of TBPX, both PPV oligomers in doped state and DSB are synthesized. ${ }^{18,19}$ As observed in Fig. $5 a_{1}$ and $b_{1}$, the IR spectrum of the PPV MCs in doped state shows a strong dependence on the angle of polarization of the IR absorption bands peaked at $\sim 885,1000-1200$, and $1510 \mathrm{~cm}^{-1}$. In comparison with Fig. $5 a_{1}$ and $b_{1}$, the following changes were observed in the IR spectra of the composites based on RGO and PPV MCs in doped state (Fig. $5 a_{2}, a_{3}$ and $b_{2}, b_{3}$ ) as the RGO weight percentage concentration in the composites mass increased: (i) a down-shift of the IR absorption bands from 885 and $1423 \mathrm{~cm}^{-1}$ to 875 and $1417 \mathrm{~cm}^{-1}$, respectively, simultaneously with the appearance of two new IR absorption bands peaked at $832-843$ and $962-966 \mathrm{~cm}^{-1}$; (ii) a gradual change of the ratio between the absorbance of the p/s polarized IR bands situated in the spectral ranges of 1350-1400 and 1450-1500 $\mathrm{cm}^{-1}$ from $0.46 / 0.39$ (Fig. $5 \mathrm{a}_{1}$ and $\mathrm{b}_{1}$ ) to 1.01/0.86 (Fig. $5 \mathrm{a}_{2}$ and $b_{2}$ ) and 1.92/1.95 (Fig. $5 a_{3}$ and $b_{3}$ ); (iii) a gradual increase in the absorbance of the p polarized IR band with the maximum at $1149-1151 \mathrm{~cm}^{-1}$; and (iv) an increase in the absorbance of the IR band with the maximum at $1510-1514 \mathrm{~cm}^{-1}$ is reported in the case of the $\mathrm{p}$ and s polarized IR spectra of the composites based on RGO and PPV in doped state.

Similar changes with those reported in the case of singlewalled carbon nanotubes covalently functionalized with PPV $^{5}$ are reported by the IR absorption spectroscopy under polarized light, when the covalent functionalization of the RGO sheets with PPV took place. Similar changes with those reported in the case of single-walled carbon nanotubes covalently functionalized with $\mathrm{PPV}^{5}$ are reported by the IR absorption spectroscopy under polarized light, when the covalent functionalization of the RGO sheets with PPV took place.

In this context, it is worth mentioning: (i) the down-shift of the IR band assigned to the vibrational mode of phenyl ring $\mathrm{C}=\mathrm{C}$ in-plane bending ${ }^{18,19}$ from $1423 \mathrm{~cm}^{-1}$ (Fig. $5 \mathrm{a}_{1}$ and $\mathrm{b}_{1}$ ) to $1417-1414 \mathrm{~cm}^{-1}$ (Fig. $5 \mathrm{a}_{3}$ and $\mathrm{b}_{3}$ ); (ii) the change of the ratio between the absorbance of the $\mathrm{p} / \mathrm{s}$ polarized IR bands assigned to the vibrational modes of phenyl ring $\mathrm{C}=\mathrm{C}$ in-plane bending ${ }^{18,19}$ and the PPV quinoid structure ${ }^{7,18,22}$ situated at 1414-1423 and $1485 \mathrm{~cm}^{-1}$, respectively, from $0.26 / 0.33$ (Fig. $5 \mathrm{a}_{1}$ and $b_{1}$ ) to 1.81/1.23 (Fig. $5 a_{2}$ and $b_{2}$ ) and 5.26/2.39 (Fig. $5 a_{3}$ and $\mathrm{b}_{3}$ ); (iii) the increase in the absorbance of the IR band assigned to the vibrational modes of phenyl ring $\mathrm{C}-\mathrm{H}$ out-of-plane bending ${ }^{18,19}$ situated at $843-832 \mathrm{~cm}^{-1}$ (Fig. $5 \mathrm{a}_{2}, \mathrm{~b}_{2}, \mathrm{a}_{3}$ and $\mathrm{b}_{3}$ ); and (iv) a down-shift of the IR band, assigned to the $E_{2 g}$, a vibrational mode ${ }^{19}$ from 1180 to $1151 \mathrm{~cm}^{-1}$ which is accompanied of an increase in its absorbance (Fig. $5 a_{1}-a_{3}$ ). These changes can be explained taking into account the reaction mechanism of the electrochemical functionalization of the RGO sheets with PPV shown in Scheme $2 S$, $\dagger$ when the formation of new covalent bonds C-C between RGO and PPV takes place.

To explain these variations and to verify the hypothesis that the electrochemical polymerization of TBPX leads to the synthesis of two reaction products, i.e., PPV oligomers in doped state and DSB, Fig. 6 shows the p and s polarized IR spectra of the synthesized electrochemical samples, which were successively interacted with the $1 \mathrm{M} \mathrm{NH}_{4} \mathrm{OH}$ solution for $5 \mathrm{~min}$. Such an interaction should lead to a de-doping of PPV in doped state, when MCs of PPV in un-doped state are anticipated to result. If this condition occurs, the $\mathrm{p}$ and s polarized IR absorption spectra
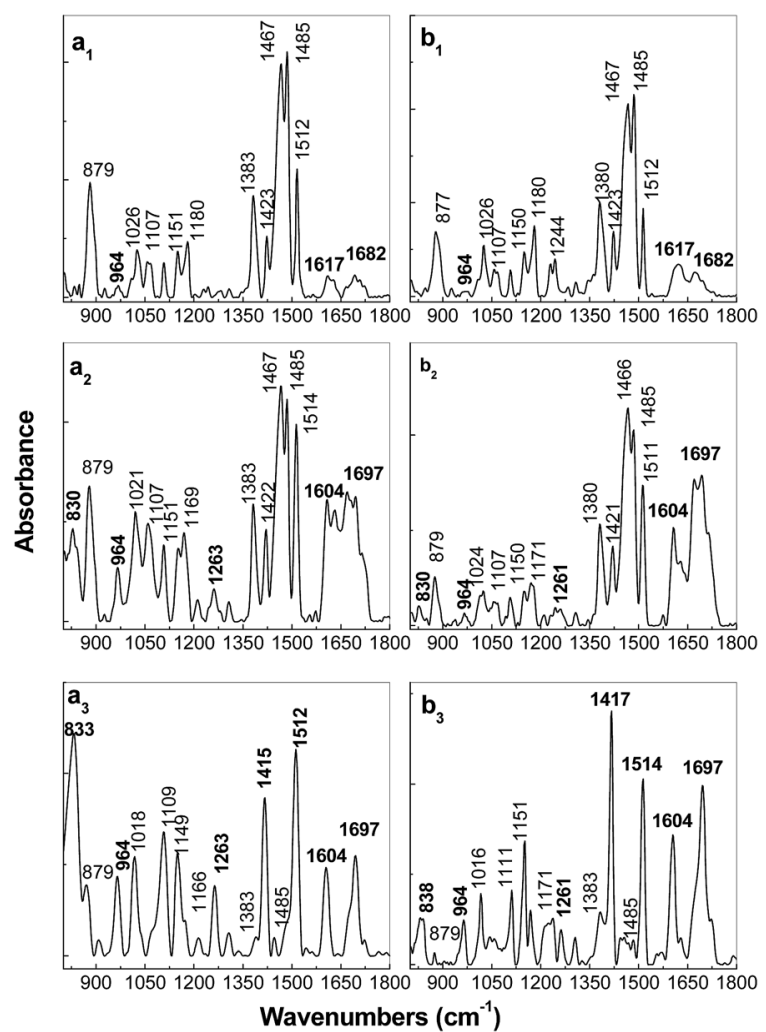

Fig. 6 The IR spectra recorded in $\mathrm{p} \mathrm{(a)} \mathrm{and} \mathrm{s} \mathrm{polarization} \mathrm{(b)} \mathrm{of} \mathrm{the}$ samples resulting from the chemical interaction of the $1 \mathrm{M} \mathrm{NH}_{4} \mathrm{OH}$ solution with the films of PPV in doped state deposited on an Au support, prepared by the electropolymerization of TBPX in the absence $\left(a_{1}\right.$ and $\left.b_{1}\right)$ and in the presence of the different weight percentage concentrations of RGO equal to $0.01 \mathrm{wt} \%\left(\mathrm{a}_{2}\right.$ and $\left.\mathrm{b}_{2}\right)$ and $0.1 \mathrm{wt} \%\left(\mathrm{a}_{3}\right.$ and $\left.\mathrm{b}_{3}\right)$. 
will be similar to those shown in Fig. 4. The interaction of the PPV in doped state with the $1 \mathrm{M} \mathrm{NH}_{4} \mathrm{OH}$ solution induces the following changes in the IR absorption spectra of Fig. 6: (i) a decrease in the absorbance of the IR band located in the spectral range of $800-850 \mathrm{~cm}^{-1}$ in the $\mathrm{p}$ polarization geometry (Fig. $5 \mathrm{a}_{1}$ and $6 \mathrm{a}_{1}$ ); (ii) a down-shift of the IR band, assigned to the $\mathrm{A}_{1 \mathrm{~g}}$ vibrational mode, from $885-887 \mathrm{~cm}^{-1}$ to $879-877 \mathrm{~cm}^{-1}$ is observed for both the $\mathrm{p}$ and $\mathrm{s}$ polarized IR spectra (Fig. $5 \mathrm{a}_{1}, \mathrm{~b}_{1}$ and $6 \mathrm{a}_{1}, \mathrm{~b}_{1}$ ); (iii) a change of the ratio between the absorbance of the IR bands located in the spectral range of $1100-1200 \mathrm{~cm}^{-1}$ $\left(I_{1151-1149} / I_{1180}\right)$ from 0.29 and 0.52 (Fig. $5 a_{1}$ and $b_{1}$ ) to 0.82 and 0.63 (Fig. $6 \mathrm{a}_{1}$ and $\mathrm{a}_{2}$ ), when the PPV IR spectra were recorded in $\mathrm{p}$ and $\mathrm{s}$ polarization geometry, respectively. Above variations reported in the $850-1500 \mathrm{~cm}^{-1}$ spectral range indicate that DSB is also electrochemical synthesized on the Au support. The successively interaction of PPV in doped state with the $1 \mathrm{M}$ $\mathrm{NH}_{4} \mathrm{OH}$ solution leads to a significant increase in the absorbance of the IR band peaked at $1518 \mathrm{~cm}^{-1}$ (Fig. $6 \mathrm{a}_{1}$ and $\mathrm{b}_{1}$ ). A careful analysis of Fig. $5 a_{1}, b_{1}$ and $6 a_{1}, b_{1}$ indicates a change of the ratio between absorbance of the IR bands peaked at 1512-1518 and $1423 \mathrm{~cm}^{-1}$, recorded under $\mathrm{p} / \mathrm{s}$ polarized light, from $0.54 / 0.81$ (Fig. $5 \mathrm{a}_{1}$ and $\mathrm{b}_{1}$ ) to $2.11 / 1.36$ (Fig. $6 \mathrm{a}_{1}$ and $\mathrm{b}_{1}$ ), when PPV in doped state has interacted with the $1 \mathrm{M} \mathrm{NH}_{4} \mathrm{OH}$ solution. This fact indicates clearly the transformation of PPV from the doped state into an un-doped state. Contrary to our expectations, an increase in the absorbance of the IR band peaked at $964 \mathrm{~cm}^{-1}$ is not observed after the interaction of PPV in doped state with the $1 \mathrm{M} \mathrm{NH}_{4} \mathrm{OH}$ solution. For the moment an explanation for this behavior is difficult to be advanced. A different behavior is observed in the case of the PPV/RGO composites synthesized by electrochemical method and successively interacted with the $1 \mathrm{M}$ $\mathrm{NH}_{4} \mathrm{OH}$ solution when an increase in absorbance of the IR band peaked at $964 \mathrm{~cm}^{-1}$ is observed in Fig. $6 a_{2}, a_{3}, b_{2}$ and $b_{3}$. Other changes observed in IR spectra of the samples resulting after the chemical interaction of $\mathrm{NH}_{4} \mathrm{OH}$ with the composites based on PPV in doped state and RGO (Fig. $6 a_{2}, a_{3}, b_{2}$ and $b_{3}$ ) consist in: (i) a gradual increase in absorbance of the IR band with maximum at $\sim 830-833 \mathrm{~cm}^{-1}$ simultaneously with the decrease in absorbance of the IR band localized at $879 \mathrm{~cm}^{-1}$; the ratio between absorbance of the IR bands peaked at $\sim 830-833$ and $879 \mathrm{~cm}^{-1}$ $\left(I_{830-833} / I_{879}\right)$ in the $\mathrm{p} / \mathrm{s}$ polarized IR spectra is equal to $0.66 / 0.39$ and 3.23/3.89 when the weight percentage concentration of RGO in the composite mass was of $0.01 \mathrm{wt} \%$ and $0.1 \mathrm{wt} \%$, respectively; (ii) a change of the value of the ratio between the absorbance of the IR bands peaked at $\sim 1151$ and $1169 \mathrm{~cm}^{-1}$ $\left(I_{1151} / I_{1169}\right)$ in the $\mathrm{p} / \mathrm{s}$ polarized IR spectra from $0.82 / 0.78$ to $2.92 /$ 2.93 when the weight percentage concentration of RGO in the composite mass was of $0.01 \mathrm{wt} \%$ and $0.1 \mathrm{wt} \%$, respectively; (iii) a gradual increase in the absorbance of the IR band with maximum at 1261-1263 $\mathrm{cm}^{-1}$; and (iv) a change of the ratios between the absorbance of the IR bands with maxima at (a) 1383 and $1422-1415 \mathrm{~cm}^{-1}\left(I_{1383} / I_{1422-1415}\right)$ from $0.72 / 0.78$ (Fig. $6 \mathrm{a}_{2}$ and $b_{2}$ ) to $9.64 / 4.83$ (Fig. $6 a_{3}$ and $b_{3}$ ) and (b) 1467-1485 and 1512$1514 \mathrm{~cm}^{-1}\left(I_{1467-1485} / I_{1512-1514}\right)$ from $0.84 / 0.66$ (Fig. $6 \mathrm{a}_{2}$ and $\left.\mathrm{b}_{2}\right)$ to 5.85/8.71 (Fig. $6 \mathrm{a}_{3}$ and $\mathrm{b}_{3}$ ) when the RGO weight percentage concentration in the composite mass was of $0.01 \mathrm{wt} \%$ and 0.1 $\mathrm{wt} \%$, respectively. In this stage of our study, it is worth mentioning that the IR bands at 833, 964, 1415, and $1514 \mathrm{~cm}^{-1}$, observed in Fig. $6 a_{2}, a_{3}, b_{2}$, and $b_{3}$, are also reported in the IR spectra of PPV in un-doped state (Fig. 4). This fact shows that as the RGO weight percentage concentration in the PPV electrochemical synthesis solution increases, the PPV MCs similar to those reported in the PPV synthesized by AC of the PPV PS are obtained to the detriment of DSB. In the case of the composite, based on PPV in doped state and $0.5 \mathrm{wt} \% \mathrm{RGO}$, electrochemical synthesized and successively interacted with the $1 \mathrm{M} \mathrm{NH}_{4} \mathrm{OH}$ solution, the increase in the absorbance of the IR band at 1417 $\mathrm{cm}^{-1}$, assigned to the phenyl ring $\mathrm{C}=\mathrm{C}$ in-plane bending vibrational mode, ${ }^{\mathbf{1 8 , 1 9}}$ indicates a hindrance steric effect induced by the covalent functionalization of the RGO sheets with MCs of PPV in un-doped state.

Returning to Fig. 4, it is worth mentioning that the $\mathrm{p}$ and $\mathrm{s}$ polarized IR spectra of the PPV films in un-doped state synthesized by the PPV PS AC method show an absorption band peaked at $1678 \mathrm{~cm}^{-1}$ with a very low absorbance (curves $\mathrm{a}_{1}$ and $\mathrm{b}_{1}$ in Fig. 4) which was assigned to the $\mathrm{C}=\mathrm{O}$ stretching vibrational mode. ${ }^{18}$ An IR absorption band, peaked at $1682 \mathrm{~cm}^{-1}$, of low absorbance, was also reported in the case of the PPV sample synthesized by electrochemical method and successively interaction with a $1 \mathrm{M} \mathrm{NH}_{4} \mathrm{OH}$ solution (Fig. $6 \mathrm{a}_{1}$ and $\mathrm{b}_{1}$ ). Regardless of the synthesis method of composites based on RGO and PPV in un-doped state, i.e. AC method (curves $\mathrm{a}_{2}-\mathrm{a}_{4}$ in Fig. 4) and electrochemical method and successively interaction with a $1 \mathrm{M}$ $\mathrm{NH}_{4} \mathrm{OH}$ solution (Fig. $6 \mathrm{a}_{2}, \mathrm{a}_{3}, \mathrm{~b}_{2}$ and $\mathrm{b}_{3}$ ), an increase in absorbance of the IR band situated in the spectral range 1650-1750 $\mathrm{cm}^{-1}$ is reported. In our opinion, the increase in absorbance of the IR band situated in the spectral range $1650-1750 \mathrm{~cm}^{-1}$ in the case of the PPV/RGO composites prepared by AC method originates in presence of reminiscent $\mathrm{C}=\mathrm{O}$ bonds in $\mathrm{RGO}$ sheets. The significant increase in absorbance of the IR band situated in the spectral range $1650-1750 \mathrm{~cm}^{-1}$, observed in the case of the sample prepared by electrochemical method and successively interacted with the $1 \mathrm{M} \mathrm{NH}_{4} \mathrm{OH}$ solution originates both in (i) the appearance of new $\mathrm{C}=\mathrm{O}$ bonds in RGO sheets resulted during the oxidation reactions in the potential range $(-2 ;+2)$ V versus the $\mathrm{Ag} / \mathrm{AgCl}$ electrode, when Au electrodes were immersed in the solutions of $0.02 \mathrm{M}$ TBPX and 0.1 M TBAB with different weight percentage concentrations of RGO in the solvent mixture of DMF and $\mathrm{H}_{2} \mathrm{O}$, having the volumetric ratio of $98: 2$ and (ii) the formation of new $\mathrm{C}=\mathrm{O}$ bonds on PPV MCs.

Additional proofs concerning the presence of PPV MCs and DSB on the Au electrode surface, depending on the synthesis method used for the preparation of the PPV/RGO composites, are shown in Fig. 7-9. The black curve in Fig. 7 shows the PL spectrum of PPV in un-doped state, obtained by the AC of the PPV PS at the conversion temperature of $300{ }^{\circ} \mathrm{C}$, which is characterized by a complex band with the maximum at $\sim 2.25 \mathrm{eV}$.

According to Fig. 8a, the de-convolution of the PL spectrum of the PPV film in un-doped state reveals four emission bands peaked at 2.42, 2.25, 2.1, and $1.96 \mathrm{eV}$. The first two PL bands with maxima at 2.42 and $2.25 \mathrm{eV}$ were assigned to the electronic emission transitions of MCs that have lengths of 5 and 7-10 RUs, respectively, whereas the last two PL bands peaking at 2.1 

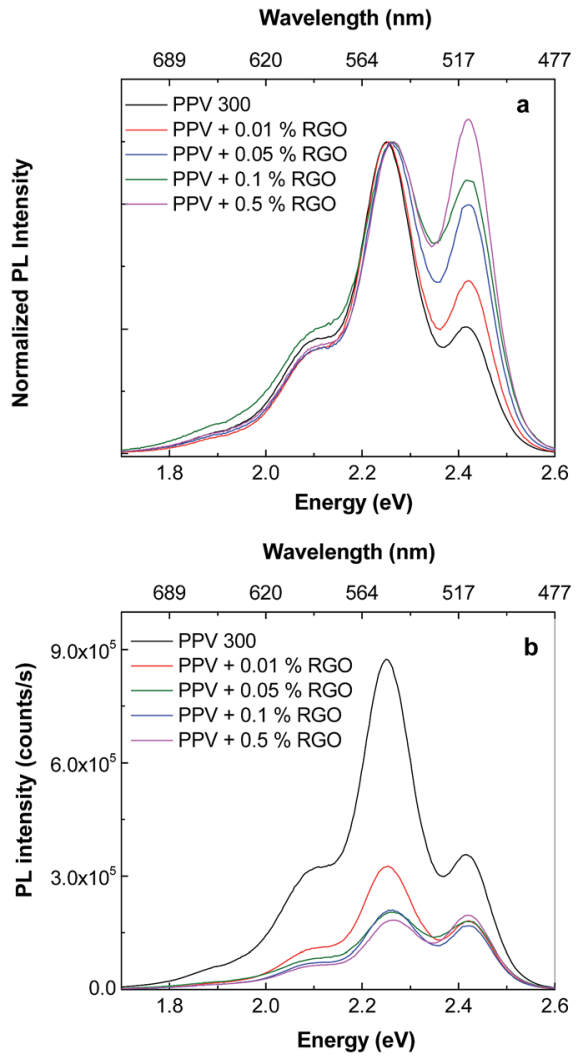

Fig. 7 The PL spectra $\left(\lambda_{\text {exc }}=440 \mathrm{~nm}(2.82 \mathrm{eV})\right.$ ) of the samples obtained by the $\mathrm{AC}$ method at $300^{\circ} \mathrm{C}$ of the PPV PS with different weight percentage concentrations of RGO: $0 \mathrm{wt} \%$ (black curve), $0.01 \mathrm{wt} \%$ (red curve), 0.05 wt $\%$ (green curve), 0.1 wt $\%$ (blue curve), and 0.5 wt $\%$ (magenta curve). (a) and (b) show above PL spectra in normalized scale and normal, respectively.

and $1.96 \mathrm{eV}$ correspond to the vibronic replica of the first and second order, respectively, of the PL band with a maximum at $2.42 \mathrm{eV} .^{22}$ In this work, MCs that have lengths of 5 and 7-10 RUs correspond the PPV backbone segments with conjugation length corresponding to the molecular structures $\left(-\mathrm{C}_{6} \mathrm{H}_{4}-\mathrm{CH}=\right.$ $\mathrm{CH}-)_{5}$ and $\left(-\mathrm{C}_{6} \mathrm{H}_{4}-\mathrm{CH}=\mathrm{CH}^{-}\right)_{7}$, respectively.

Fig. $1 \mathrm{~S} \dagger$ highlights both a change in the shape of the PPV PL spectrum and a decrease in its intensity as the RGO weight percentage concentration in the composite mass increases. A similar effect of PPV PL quenching was reported in the case of PPV/SWCNT composites synthetized by the AC of the PPV PS with different SWCNT weight percentage concentrations. ${ }^{23}$

According to Fig. 1S, $\uparrow$ the changes in the profile of the PPV PL spectrum are marked in the presence of RGO, when the values of the ratio between the relative intensities of the two emission bands peaked at 2.25 and $2.42 \mathrm{eV}\left(I_{2.25} / I_{2.42}\right)$ vary from 2.4 (Fig. $1 \mathrm{~S}(\mathrm{a}) \dagger$ ) to 1.25 (Fig. $1 \mathrm{~S}(\mathrm{~b}) \dagger$ ) and 0.95 (Fig. $1 \mathrm{~S}(\mathrm{c}) \dagger$ ). The increase in the relative intensity of the PL band at $2.42 \mathrm{eV}$ with respect to the PL band with maximum at $2.25 \mathrm{eV}$ (Fig. 1S†) is assigned to the increase of the short and isolated segments of PPV with the length of $5 \mathrm{RU}$ in the presence of RGO. This assignment was make taking into account ref. 24, when a similar behavior of PL spectra of the composites obtained by

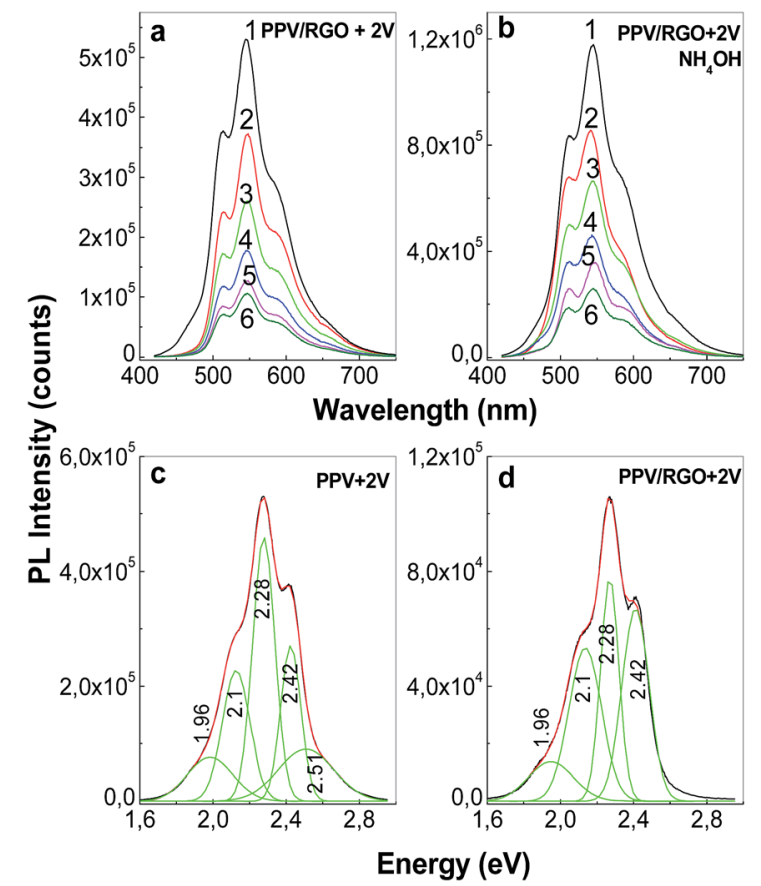

Fig. 8 (a) The PL spectra of the films electrosynthesized onto the $A u$ electrode immersed in the solution of $0.02 \mathrm{M} \mathrm{TBPX}$ and $0.1 \mathrm{M} \mathrm{TBAB}$ in DMF : $\mathrm{H}_{2} \mathrm{O}$ in the absence (curve 1) and presence of different weight percentage concentrations of RGO, i.e., 0.01 wt\% (curve 2), 0.025 wt\% (curve 3), $0.05 \mathrm{wt} \%$ (curve 4), $0.1 \mathrm{wt} \%$ (curve 5), and $0.5 \mathrm{wt} \%$ (curve 6). (b) shows the PL spectra of these films, chemically interacted with the $1 \mathrm{M} \mathrm{NH}_{4} \mathrm{OH}$ solution. The deconvolution of the PL spectra of the films of PPV and PPV/RGO is shown in (c) and (d).

AC of the PPV precursor solutions with different SWNTs weight percentage concentrations, was reported. For the electrochemical synthesized samples, a change of the $I_{2.25} / I_{2.42}$ ratio from 1.7 (Fig. 8c) to 1.15 (Fig. 8d) is reported in the presence of RGO. The difference between the values of the $I_{2.25} / I_{2.42}$ ratio in the case of the two methods, i.e. AC $(0.95$, Fig. $1 \mathrm{~S}(\mathrm{c}) \dagger)$ and electrochemical way (1.15, Fig. $8 \mathrm{~d})$, can be a consequence of the reaction mechanisms of the two methods. In this context, it is worth mentioning that in comparison with AC method (Scheme $1 \mathrm{~S} \dagger$ ), each reduction reaction shown in Scheme $2 S, \uparrow$ leads to obtain of two reaction products from which only one allows further growth of PPV MCs.

Depending on the synthesis method used to prepare the films of PPV in un-doped state, i.e. (i) AC method and (ii) the electrochemical way followed by a successively interaction with a $1 \mathrm{M} \mathrm{NH}_{4} \mathrm{OH}$ solution, the PL intensity varies from 900.000 counts (black curve in Fig. 7b) to 1.176 .530 counts (curve 1 in Fig. 8b), respectively. According to the yearly studies reported by M. Anni et al. ${ }^{25}$ the generation of carbonyl groups on PPV MCs induces an enhancement of PPV PL. Taking into account this progress, a first conclusion is that the PPV film in un-doped state synthetized by AC method contains less $\mathrm{C}=\mathrm{O}$ groups onto MCs in comparison with the electrochemical synthetized PPV sample and successively interacted with the $1 \mathrm{M} \mathrm{NH}_{4} \mathrm{OH}$ solution. This sentence is in good agreement with our results obtained by IR spectroscopy in polarized light (Fig. 4 and 6). 

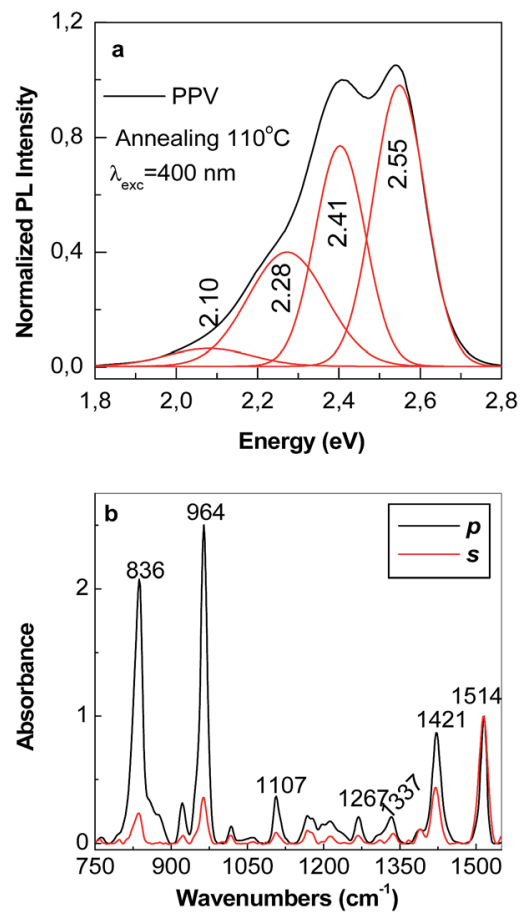

Fig. 9 The PL spectrum of the sample obtained by AC of the PPV PS at $110^{\circ} \mathrm{C}(\mathrm{a})$ and its $\mathrm{p}$ and $\mathrm{s}$ polarized IR spectrum (black and red curves in (b)).

According to Fig. 8a and c, the PL spectrum of the sample synthesized by the electrochemical method, when CVs were stopped at the potential of $+2 \mathrm{~V}$ versus $\mathrm{Ag} / \mathrm{AgCl}$, shows that in the spectral range of 420-775 $\mathrm{nm}$ (2.95-1.6 eV), five emission bands peaked at 1.96, 2.1, 2.28, 2.42, and $2.51 \mathrm{eV}$. Thus far, a PL band around $2.51 \mathrm{eV}$ was reported both in the case of the PPV MCs synthesized by the AC of PPV PS at the conversion temperature of $120{ }^{\circ} \mathrm{C}$ (ref. 23) and in DSB. ${ }^{23,26}$ As demonstrated by A. Sreeram et al., a low conversion takes place in the case of PPV PS $\mathrm{AC}$ at the temperature of $110{ }^{\circ} \mathrm{C} .{ }^{27}$ According to Fig. 9a, the PL spectrum of PPV synthesized by the AC method at temperature of $110{ }^{\circ} \mathrm{C}$ shows four emission bands peaked at 2.55, 2.41, 2.28, and $2.1 \mathrm{eV}$, the most intense emission band being that situated in the 2.45-2.8 eV spectral range, which is assigned to the PPV MCs with the length of 4 RUs. ${ }^{23,24}$

Fig. 9b reveals that the $\mathrm{p}$ and $\mathrm{s}$ polarized IR spectra of the sample obtained by the AC of the PPV PS at the conversion temperature of $110^{\circ} \mathrm{C}$ show all IR absorption bands reported in the case of the PPV films prepared by the same method at the temperature of $300{ }^{\circ} \mathrm{C}$ (black curves in Fig. $4 \mathrm{a}$ and b). Fig. 9b reveals that the $\mathrm{p}$ and $\mathrm{s}$ polarized IR spectra of the sample obtained by the AC of the PPV PS at the conversion temperature of $110{ }^{\circ} \mathrm{C}$ show all IR absorption bands reported in the case of the PPV films prepared by the same method at the temperature of $300{ }^{\circ} \mathrm{C}$ (black curves in Fig. $4 \mathrm{a}$ and b). Considering that the $\mathrm{p}$ and s polarized IR spectra of the PPV film, prepared at the conversion temperatures of $110{ }^{\circ} \mathrm{C}$ and $300{ }^{\circ} \mathrm{C}$, do not show IR bands peaked at 885-877, 1025-1032, 1068, 1105-1109, 1149, 1180, 1380-1394, and 1466-1485 $\mathrm{cm}^{-1}$, and they are observed only in the case of DSB, we assign these IR bands to the substituted DSB that results during the PPV electrochemical synthesis in the presence of RGO (Scheme $2 \mathrm{~S} \dagger$ ). As observed in Fig. $8 \mathrm{~b}$, the successive interaction of the sample, synthetized by electrochemical method and in the absence of RGO, with the $1 \mathrm{M} \mathrm{NH}_{4} \mathrm{OH}$ solution does not induce a change in the profile of the emission band situated in the 420-775 $\mathrm{nm}$ spectral range. The de-doping process of the macromolecular compound in the presence of the $1 \mathrm{M} \mathrm{NH} \mathrm{NH}_{4} \mathrm{OH}$ solution is evidenced by the increase in the intensity of the PL spectrum from 529.472 counts (curve 1, Fig. 8 a) to 1.179 .410 counts (curve 1, Fig. 8 b) when the MCs of PPV in un-doped state are deposited on the Au electrode surface. These changes show that two compounds are synthesized by the electrochemical polymerization of TBPX onto an Au electrode when CVs were stopped at the potential of +2 V versus $\mathrm{Ag} / \mathrm{AgCl}$ : a PPV in doped state and DBS. A change in the profile of the PL spectra of the samples obtained by electrochemical polymerization of TBPX in the presence of RGO is remarked by the existence of only four emission bands peaked at 1.96, 2.1, 2.28, and $2.42 \mathrm{eV}$ (Fig. 8d). The disappearance of the emission band with the maximum at $2.51 \mathrm{eV}$ in the case of the composites based on PPV in doped state and different RGO weight percentage concentration is in good accordance with the IR studies presented above, which indicates that an inhibition of the DSB formation onto the Au electrode surface occurs.

Using anisotropic PL measurements in the following, an estimation of the wrapping angle of RGO sheets with PPV MCs is shown. Using vertical $(\mathrm{V})$ and horizontal $(\mathrm{H})$ polarization $\mathrm{PL}$ excitation beams, the PL intensity in the $\mathrm{V}$ and $\mathrm{H}$ polarization
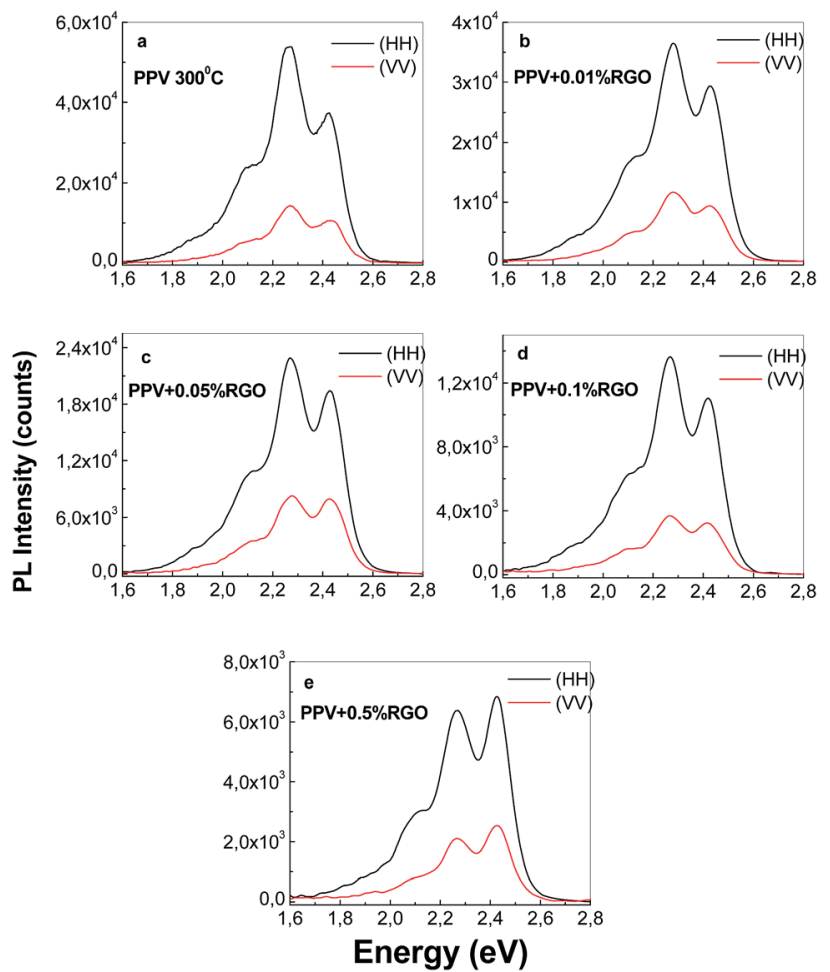

Fig. 10 The polarized PL spectra $\left(\lambda_{\text {exc }}=440 \mathrm{~nm}\right.$ ) of the films deposited on Au supports, resulting from the $A C$ at $300^{\circ} \mathrm{C}$ of the PPV PS with different weight percentage concentrations of RGO: 0 wt\% (a), $0.01 \mathrm{wt} \%$ (b), $0.05 w t \%$ (c), $0.1 \mathrm{wt} \%$ (d), and $0.5 \mathrm{wt} \%$ (e). 


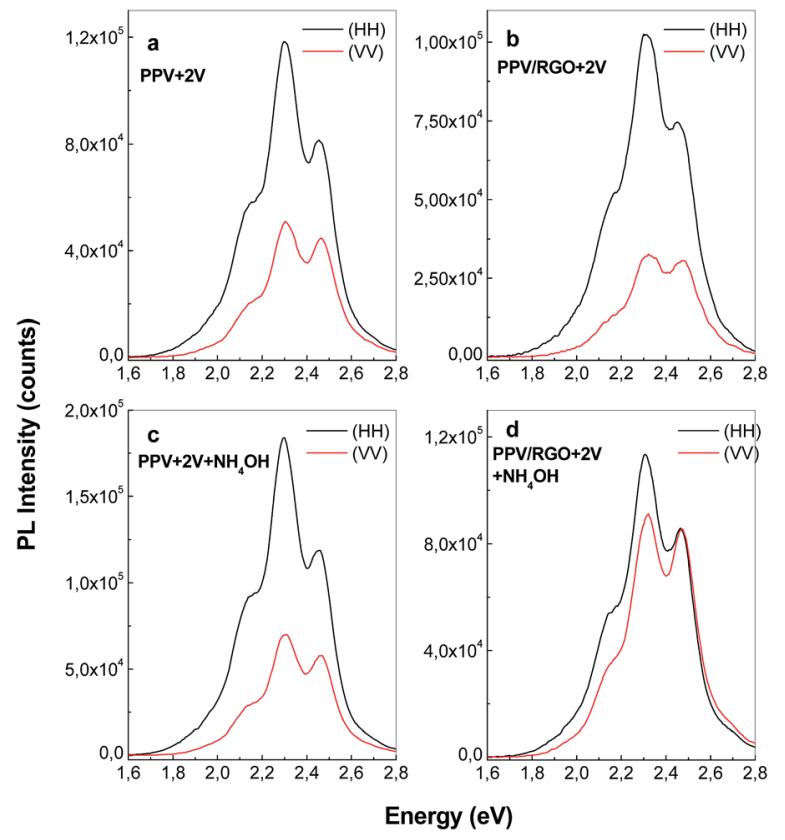

Fig. 11 The polarized PL spectra of the films of PPV in doped state (a) and the composite, electrosynthesized onto the $\mathrm{Au}$ electrode, immersed in the solution of $0.02 \mathrm{M} \mathrm{TBPX}, 0.1 \mathrm{M} \mathrm{TBAB}$, and 0.5 wt\% RGO in DMF : $\mathrm{H}_{2} \mathrm{O}$ (b). (c) and (d) show the polarized PL spectra of the two samples, chemically interacted with the $1 \mathrm{M} \mathrm{NH}_{4} \mathrm{OH}$ solution.

geometry was measured in this order. A dependence of the polarization of the PL spectra both in the case of PPV and its composites with RGO, synthesized by AC of the PPV PS and electrochemical polymerization of TBPX, is highlighted in Fig. 10 and 11. The previously studies reported by I. Orion et al. have demonstrated that PPV PS AC method allows the obtaining of the oriented polymer films. ${ }^{19} \mathrm{~A}$ significant role in the obtaining the oriented polymer films was reported to be played of the PPV inter-chain interactions. ${ }^{28}$ At present, it is known that the PPV PS AC involves a liquid crystalline phase that induces alignment predominantly along the rubbing director. ${ }^{29}$ This fact induces as the PPV PL intensity measured with the excitation and emission polarizers mounted horizontal in spectrophotometer $\left(I_{\mathrm{HH}}\right)$ to be higher than those of light intensity measured with excitation and emission polarizers mounted vertically $\left(I_{\mathrm{VV}}\right)^{28,29}$

Fig. 10a confirms this behavior for the films prepared by PPV PS AC. The anisotropy $(r)$ and the polarization $(P)$ were calculated according to the eqn (1) and (2): ${ }^{13}$

$$
\begin{gathered}
r=\left(I_{\mathrm{VV}}-G I_{\mathrm{VH}}\right) /\left(I_{\mathrm{VV}}+2 G I_{\mathrm{VH}}\right) \\
P=3 r /(2+r)
\end{gathered}
$$

where: (i) $I_{\mathrm{VV}}$ corresponds to the light intensity with excitation and emission polarizers mounted vertically and $I_{\mathrm{VH}}$ corresponds to the light intensity with the excitation polarizer vertical and emission polarizer horizontal in the spectrophotometer and (ii) $G$ is an instrument-dependent calibration factor which is defined as follows: $G=I_{\mathrm{HV}} / I_{\mathrm{HH}}$, where $I_{\mathrm{HV}}$ corresponds

to the light intensity measured using an excitation polarizer horizontal and the emission polarizer vertical and $I_{\mathrm{HH}}$ corresponds to the light intensity for the excitation and emission polarizers mounted horizontally.

For single-phonon excitation, the angle of the binding $\left(\theta_{\mathrm{PL}}\right)$ of PPV onto RGO sheet surfaces was calculated according to eqn (3):

$$
r=0.4\left[\left(3 \cos ^{2} \theta_{\mathrm{PL}}-1\right) / 2\right]
$$

This equation indicates that the $r$ values can be equal with -0.2 and +0.4 , when the $\theta_{\mathrm{PL}}$ angle may vary from $90^{\circ}$ to $0^{\circ}$.

In samples prepared by the AC of the PPV PS, one observes that the $r$ values are easily different of 0.4 . When the $r$ value is 0.4 the excitation and emission transition dipoles are aligned, namely parallel to the basal plane of RGO.

A decrease from 0.373 to 0.238 , as increasing the RGO weight percentage concentration in the composite mass is reported. A smaller value for $r$, equal with 0.207 , is reported in the case of the PPV electrochemical synthesized in the presence of RGO, according to Table 2 . This experimental fact leads to an angle between the molecule's absorption and emission dipoles equal with $34^{\circ}$, which indicates that the PPV excitation dipole is not parallel to the basal plane of RGO. Considering the PL band peaked at $2.41 \mathrm{eV}$, the values of the $r$ and $\theta_{\mathrm{PL}}$ parameters are summarized for the PPV and its composites with RGO, synthesized by the two methods, in Table 2 . The $\theta_{\mathrm{PL}}$ values vary when the RGO weight percentage concentration is changed from 0 to $0.5 \mathrm{wt} \%$ in the composite mass from: (i) $12^{\circ}$ to $31^{\circ}$, in the RGO sheets non-covalently functionalized with PPV in undoped state; and (ii) $28^{\circ}$ to $34^{\circ}$, in the RGO sheets covalently functionalized with PPV in doped state. Regardless of the synthesis route, the $\theta_{\mathrm{PL}}$ values of the composites based on PPV in un-doped or doped state and RGO with a weight percentage concentration of $0.5 \mathrm{wt} \%$ are close. The growth of the $\theta_{\mathrm{PL}}$ value as the RGO weight percentage concentration increases in the composite mass is the result of the $\pi-\pi *$ interactions between

Table 2 The intensities values of the PL band at $2.42 \mathrm{eV}\left(/_{\mathrm{HH}}\right.$, and $\left./ \mathrm{VV}\right)$, the anisotropy $(r)$, and wrapping angle of RGO sheets with PPV MCs $\left(\theta_{\mathrm{PL}}\right)$ when the synthesis methods used are the AC of PPV PS and electrochemical polymerization of TBPX in the presence of different RGO weight percentage concentrations

\begin{tabular}{lllll}
\hline Sample & $\begin{array}{l}I_{\mathrm{HH}} \\
\text { (counts) }\end{array}$ & $\begin{array}{l}I_{\mathrm{VV}} \\
\text { (counts) }\end{array}$ & $r$ & $\begin{array}{l}\theta_{\mathrm{PL}} \\
\text { (degree) }\end{array}$ \\
\hline
\end{tabular}

\section{AC method of PPV PS} PPV

$\mathrm{PPV}+0.01 \mathrm{wt} \% \mathrm{RGO}$

$\mathrm{PPV}+0.05 w \mathrm{t} \% \mathrm{RGO}$

54.100

14.755

0.373

35.200

12.100

0.369

23.200

9.320

$\mathrm{PPV}+0.1 \mathrm{wt} \% \mathrm{RGO}$

11.922

3.322

0.320

$\mathrm{PPV}+0.5 \mathrm{wt} \% \mathrm{RGO}$

7.422

2.472

0.299

0.238

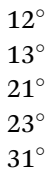

Electrochemical polymerization of TBPX, $30 \mathrm{CVs}$

PPV

PPV/RGO $0.1 \mathrm{wt} \%$

$\mathrm{PPV}+1 \mathrm{M} \mathrm{NH}_{4} \mathrm{OH}$

PPV/RGO $0.1 \mathrm{wt} \%$

$+1 \mathrm{M} \mathrm{NH}_{4} \mathrm{OH}$

$\begin{array}{rrrr}83.100 & 45.600 & 0.268 & 28^{\circ} \\ 75.800 & 31.800 & 0.207 & 34^{\circ} \\ 120.000 & 59.300 & 0.261 & 29^{\circ} \\ 87.102 & 86.522 & 0.217 & 33^{\circ}\end{array}$

$\begin{array}{llll}87.102 & 86.522 & 0.217 & 33^{\circ}\end{array}$ 
the phenyl groups of PPV and the RGO sheets and the nonplanarity of PPV MCs. $^{21}$ In comparison with composites synthesized by AC of PPV PS in the presence of RGO, the higher values of $\theta_{\mathrm{PL}}$ are reported in the electrochemical synthesized samples as a consequence of the co-generation of PPV in doped state and DSB when additional $\pi-\pi^{*}$ interactions between the phenyl groups of DSB and the RGO sheets are invoked.

Concerning the adsorption of the films of PPV/RGO composite, with the same RGO weight percentage concentration on the Au electrode surface, different values of the orientation angle of the transition dipole moment vector for the four IR absorption bands at $\sim 837,963,1423$, and $1514 \mathrm{~cm}^{-1}$ are reported as depending on the synthesis methods of these materials. Thus, in the case of the sample of RGO/PPV in undoped state obtained by the chemical interaction of the $\mathrm{NH}_{4} \mathrm{OH}$ solution with the composite based on PPV in doped state and $0.1 \mathrm{wt} \%$ RGO, prepared by electrochemical route, the calculated values of the orientation angle of the transition dipole moment vector for the four IR absorption bands at $\sim 837$, 963,1423 , and $1514 \mathrm{~cm}^{-1}$ are equal with $63^{\circ}, 49^{\circ}, 33^{\circ}$ and $42^{\circ}$, respectively. Significant differences for these values are remarked versus those reported for the composites based on PPV in un-doped state and RGO prepared by the AC method (Table 1). The higher difference is noted for the orientation angle of the transition dipole moment vector of the IR absorption band, assigned to the vibrational mode of trans-vinylene C-H out-of-plane bending, ${ }^{18,19}$ with a maximum at $\sim 963 \mathrm{~cm}^{-1}$, when RGO sheets were covalently functionalized with PPV in un-doped state. These differences indicate a preferential orientation on the Au support as a consequence of the chemical adsorption of PPV in un-doped state onto the RGO sheet surface.

\section{Conclusions}

This paper reported new results concerning the influence of RGO on the optical properties of PPV in doped or un-doped state. Using surface enhanced Raman scattering, FTIR spectroscopy in the grazing angle incident reflection geometry and photoluminescence, it is demonstrated that:

(i) The AC of the PPV PS with different RGO weight percentage concentrations results in the composites based on PPV in un-doped state and RGO as demonstrated by the SERS studies and FTIR spectroscopy in the grazing angle incident reflection geometry; a PPV PL quenching effect is reported in the presence of RGO. The polarized PL measurements indicate that wrapping angle of RGO sheets with PPV MCs $\left(\theta_{\mathrm{PL}}\right)$, via the $\pi-\pi^{*}$ interactions between the phenyl groups of PPV in undoped state and the RGO sheets, varies from $12^{\circ}$ to $31^{\circ}$ when the RGO weight percentage concentration is changed from 0 to $0.5 \mathrm{wt} \%$, respectively;

(ii) Two reaction products, i.e., a PPV in doped state and DSB, were evidenced by FTIR spectroscopy to result when the electrochemical polymerization of TBPX onto an Au electrode was performed by cyclic voltammetry and a stopping of CVs at the potential of $+2 \mathrm{~V}$ versus $\mathrm{Ag} / \mathrm{AgCl}$ was carried out; (iii) Using correlated studies of PL and IR spectroscopy, a decrease in the DSB weight in favor of the PPV in doped state was demonstrated to occur as the RGO weight percentage concentration increased in the electrochemical synthesis solution; the increase in the absorbance of the IR band with a maximum at $1417 \mathrm{~cm}^{-1}$, assigned to the phenyl ring $\mathrm{C}=\mathrm{C}$ inplane bending vibrational mode, in the composite based on PPV in doped state and $0.5 \mathrm{wt} \%$ RGO, electrochemically synthetized and successively interacted with the $1 \mathrm{M} \mathrm{NH}_{4} \mathrm{OH}$ solution, indicates that a hindrance steric effect is induced by the covalent functionalization of the RGO sheets with PPV MCs. The polarized PL measurements demonstrated that the wrapping angle of RGO sheets with PPV MCs $\left(\theta_{\mathrm{PL}}\right)$ varies from $28^{\circ}$ to $34^{\circ}$ when the RGO weight percentage concentration is changed from 0 to $0.5 \mathrm{wt} \%$, respectively.

(iv) The different values of the orientation angle of the transition dipole moment vector for the IR absorption bands peaked at 833, 964, 1415 and $1514 \mathrm{~cm}^{-1}$, in composites of the type RGO non-covalently functionalized with PPV in un-doped state and RGO covalently functionalized with PPV in doped state, deposited onto Au supports, were reported.

\section{Acknowledgements}

This work was funded by the Romanian National Authority for Scientific Research, CNCS-UEFISCDI, Module III Bilateral Cooperation, Humbert Curien-Brancusi project, no. 1027/ 26.06.2014 and Core Program 2016-2017, project PN16-480101.

\section{References}

1 B. H. Wee and J. D. Hong, Adv. Funct. Mater., 2013, 23, 46574666.

2 B. H. Wee and J. D. Hong, Langmuir, 2014, 30, 5267-5275.

3 R. Ou, R. A. Gerhardt and R. J. Samuels, J. Polym. Sci., Part B: Polym. Phys., 2004, 42, 98-116.

4 L. O. Peres, H. Varela, J. R. Garcia, M. R. Fernandes, R. M. Toresi, F. C. Nart and J. Gruber, Synth. Met., 2001, 118, 65-70.

5 M. Baibarac, I. Baltog, M. Ilie, B. Humbert, S. Lefrant and C. Negrila, J. Phys. Chem. C, 2016, 120, 5694-5705.

6 H. Ago, K. Petritsch, M. S. P. Shaffer, A. H. Windle and R. H. Friend, Adv. Mater., 1999, 11, 1281-1285.

7 M. R. Fernandes, J. R. Garcia, M. S. Schultz and F. C. Nart, Thin Solid Films, 2005, 474, 279-284.

8 M. Baitoul, J. Wery, J. P. Buisson, G. Arbackle, H. Shah, S. Lefrant and M. Hamdoume, Polymer, 2000, 41, 6955-6964.

9 A. G. Grimsdale and A. B. Holmes, in Conjugated Polymers Theory, Synthesis, Properties and Characterization, Handbook of Conducting Polymers, ed. T. A. Skotheim and J. R. Reynolds, CRC Press, New York, 2006, vol. 2.

10 I. Smaranda, A. M. Benito, W. K. Maser, I. Baltog and M. Baibarac, J. Phys. Chem. C, 2014, 118, 25704-25717.

11 D. Comoretto, C. Soci, F. Marabelli, A. Mikhailovsky and D. Moses, Synth. Met., 2005, 153, 281-284.

12 P. A. Filho, A. Marletta, L. Akcelrud Jr and O. N. Oliveira, Chem. Phys. Lett., 2014, 605-606, 147-151. 
13 M. J. Shea, R. D. Mehlenbacher, M. T. Zanni and M. S. Arnold, J. Phys. Chem. Lett., 2014, 5, 3742-3749.

14 D. C. Marcano, D. V. Kosynkin, J. M. Berlin, A. Sinitskii, Z. Sun, A. Slesarev, L. B. Alemany, W. Lu and J. M. Tour, ACS Nano, 2010, 4, 4806-4816.

15 S. Eigher, C. Dotzer and A. Hirsch, Carbon, 2012, 50, 36663673.

16 J. D. Stenger-Smith, P. W. Lenz and G. Wegner, Polymer, 1989, 30, 1048-1053.

17 E. Mulazzi, A. Ripamonti, J. Wery, B. Dulieu and S. Lefrant, Phys. Rev. B: Condens. Matter Mater. Phys., 1999, 60, 1651916525.

18 D. D. C. Bradley, R. H. Friend, H. Lindenberger and S. Roth, Polymer, 1986, 27, 1709-1713.

19 I. Orion, J. P. Buisson and S. Lefrant, Phys. Rev. B: Condens. Matter Mater. Phys., 1998, 57, 7050-7065.

20 M. Baibarac, I. Baltog, J. Wery, S. Lefrant and J. Y. Mevellec, J. Phys. Chem. C, 2012, 116, 25337-25345.

21 R. I. Venkatanarayanan, S. Krishnan, A. Sreeram, P. A. Yuya, N. G. Patel, A. Tandia and J. B. McLaughlin, Macromol. Theory Simul., 2016, 25, 238-253.
22 P. Damlin, C. Kvarnstrom and A. Ivaska, Electrochim. Acta, 1999, 44, 4087-4097.

23 J. Wery, H. Aarab, S. Lefrant, E. Faulques, E. Mulazzi and R. Perego, Phys. Rev. B: Condens. Matter Mater. Phys., 2003, 67, 115202.

24 F. Massuyeau, H. Aarab, L. Mihut, S. Lefrant, E. Faulques, J. Wery, E. Mulazzi and R. Perego, J. Phys. Chem. C, 2007, 111, 15111-15118.

25 M. Anni, G. Gigli, R. Cingolani, Y. G. Gobato, A. Vercik, A. Marletta, F. G. E. Guimaras and R. M. Faria, Phys. Rev. B: Condens. Matter Mater. Phys., 2003, 68, 035215.

26 N. F. Colaneri, D. D. C. Bradley, R. H. Friend, P. L. Burn, A. B. Holmes and C. W. Spangler, Phys. Rev. B: Condens. Matter Mater. Phys., 1990, 42, 11670-11681.

27 A. Sreeram, N. G. Patel, R. I. Venkatanarayanan, S. J. DeLuca, P. A. Yuya and S. Krishnan, Polym. Test., 2014, 37, 170-178.

28 D. Comoretto, C. Soci, F. Marabelli, A. Mikhailovsky and D. Mores, Synth. Met., 2005, 153, 281-284.

29 Y. H. Yao, S. H. Yang and C. S. Hsu, Polymer, 2006, 47, 82978308. 